\title{
Avaliação de genótipos de batata para resistência ao vírus $\mathbf{Y}^{\mathbf{1}}$.
}

\author{
Julio Daniels ${ }^{2}$ \\ Embrapa Clima Temperado, Caixa Postal 403, 96.001-970 Pelotas - RS. e.mail: daniels@cpact.embrapa.br
}

\section{RESUMO}

$\mathrm{O}$ vírus Y da batata (Potato virus $Y$ ou PVY) é uma das principais causas da degenerescência da batata no Brasil. Com o objetivo de determinar, nas condições do Rio Grande do Sul, a resistência de campo de genótipos de batata à infecção pelo PVY, avaliaram-se, na presença de infectores e durante dois plantios consecutivos de primavera, quinze cultivares e clones de batata. A detecção de PVY foi efetuada por meio de testes sorológicos (DAS-ELISA). As cultivares e clones avaliados comportaram-se da seguinte forma: Cristal e 2CRI-1149-1-79, resistentes; Astrid, Baraka, Baronesa, Catucha, Macaca, Monte Bonito, Santo Amor, Trapeira e 2AC-917-7-80, resistência intermediária; Bintje, Cerrito Alegre e Monalisa, suscetíveis; e Achat, muito suscetível.

Palavras chave: Solanum tuberosum L., Potato virus $Y, P V Y$.

\section{ABSTRACT}

Evaluation of potato genotypes for resistance to Potato virus $\boldsymbol{Y}$.

Potato virus $Y$ (PVY) is considered one of the main causes of potato degeneration in Brazil. To determine the field resistance of potato genotypes to PVY, in Rio Grande do Sul, Brazil, fifteen clones and cultivars were tested during two consecutive spring planting seasons. PVY detection was done by serological tests (DAS-ELISA). Cultivars and lines performed as follows: Cristal and 2CRI-1149-179, resistant; Astrid, Baraka, Baronesa, Catucha, Macaca, Monte Bonito, Santo Amor, Trapeira and 2AC-917-7-80, intermediate resistance; Bintje, Cerrito Alegre and Monalisa, susceptible; and Achat, extremely susceptible.

Keywords: Solanum tuberosum L., Potato virus $Y, P V Y$.

\section{(Aceito Para Publicação em 26 de maio de 2.000)}

Para que o cultivo de batata atinja altas produtividades, a sanidade da batata-semente é fundamental. Nas principais regiões produtoras de batata do país a 'semente' degenera muito rapidamente, exigindo freqüentes renovações dos tubérculos para o plantio, sendo que a principal razão dessa degeneração é a infecção por vírus, com destaque para o vírus do enrolamento da folha da batata (Potato leafroll virus ou PLRV) e para o vírus Y da batata (Potato virus $Y$ ou PVY) (Daniels, 1995; Figueira, 1995; Souza Dias, 1995). Este fato faz com que o custeio da lavoura de batata seja muito elevado, pois as 'sementes' representam de 30 a $50 \%$ do seu valor, encarecendo a produção. Por outro lado, principalmente os produtores do segmento agricultura familiar não fazem a renovação das 'sementes' com a freqüência necessária, e plantam tubérculos com altos índices de infecção por viroses, resultando em baixas produtividades.

A infecção pelo PVY em lavouras de batata de Minas Gerais e de São Paulo vem crescendo em importância (Figueira, 1995; Souza-Dias, 1995) e, mesmo no Rio Grande do Sul, onde a incidên- cia deste vírus era praticamente nula (Daniels \& Castro, 1984), o problema vem aumentando consideravelmente (Daniels, 1996). O controle desta virose é dificultado pela ausência de invernos rigorosos no país, o que favorece a multiplicação dos afídeos vetores, cujo combate é ineficiente na contenção da doença.

As estirpes de PVY podem ser divididas em três grupos principais, reconhecidos como $\mathrm{PVY}^{0}, \mathrm{PVY}^{\mathrm{N}}$ e $\mathrm{PVY}^{\mathrm{C}}$. As estirpes de $\mathrm{PVY}^{0}$, ou comuns, porque são mundialmente disseminadas, causam sintomas típicos em batata, incluindo mosaico, necrose das nervuras, senescência e queda das folhas infectadas. As estirpes de PVY ${ }^{\mathrm{N}}$, ou necróticas em fumo, são mais restritas na sua distribuição geográfica, e causam mosqueado leve nas folhas de batata, que passa muitas vezes despercebido aos erradicadores e certificadores de batata-semente (Rose et al., 1987). As estirpes de $\mathrm{PVY}^{\mathrm{C}}$ tem a sua distribuição mais reduzida do que os dois grupos citados e a sua caracterização é ambígua. Alguns isolados de $\mathrm{PVY}^{\mathrm{C}}$ causam reações de hipersensibilidade em cultivares de batata e outros não são transmissíveis por afídeos, fatores que limitam sua dis- seminação, influenciando a epidemiologia desta virose (Ellis et al., 1997). Embora alguns autores tenham observado variabilidade serológica entre estes grupos, não encontraram diferenças consistentes nos testes serológicos quando utilizaram anti-soros policlonais. Porém, com a disponibilidade de anticorpos monoclonais, foi possível caracterizar serologicamente a maioria dos isolados (Rose et al., 1987; McDonald \& Kristjansson, 1993; Ellis et al., 1997).

A resistência ao PVY é baseada nos genes $\mathrm{N}$ e $\mathrm{R}$, que conferem reações de hipersensibilidade ao hospedeiro. Os genes Ny são de expressão variável e parecem ser dependentes da estirpe do vírus, ao contrário do gene Ry que confere imunidade (Foxe, 1992).

Para determinação da resistência relativa ao PVY em batata, também chamada de resistência de campo, foram utilizados experimentos de exposição à infecção, conforme descrições de Bagnall \& Tai (1986). O objetivo deste trabalho foi determinar a resistência relativa de quinze cultivares e clones de batata ao PVY sob as condições naturais da Região Sul do RS.

\footnotetext{
${ }^{1}$ Trabalho parcialmente financiado pela Fundação de Amparo à Pesquisa do Rio Grande do Sul (FAPERGS).

${ }^{2}$ Bolsista do Conselho Nacional de Pesquisa (CNPq).
} 


\section{MATERIAL E MÉTODOS}

Os tubérculos das cultivares e clones selecionados utilizados nesta pesquisa (Tabela 1), isentos de infecção pelo PVY, foram obtidos na Embrapa Clima Temperado, conforme tecnologia já descrita (Costa et al., 1989; Daniels, 1994), multiplicados em áreas isoladas e armazenados por cerca de oito meses em câmara fria $\left(4^{\circ} \mathrm{C}, 85 \%\right.$ de umidade relativa), para equilíbrio do estado fisiológico.

Os tubérculos infectados naturalmente com as estirpes $\mathrm{PVY}^{0}$ e $\mathrm{PVY}^{\mathrm{N}}$, foram selecionados de plantas de batata oriundas de experimentos realizados na Embrapa Clima Temperado e em lavouras da Região Sul do RS. Após a confirmação da infecção através de testes serológicos (DAS-ELISA), os tubérculos foram multiplicados em áreas isoladas e armazenados conforme descrito anteriormente para os tubérculos sadios. A caracterização dos isolados foi realizada biologicamente, através de inoculação mecânica nas plantas indicadoras Chenopodium amaranticolor Coste \& Reyn., C. quinoa Willd. e Nicotiana tabacum L. 'Havana', conforme indicações de Delhey (1982) e de McDonald \& Kristjansson (1993), e serologicamente, com um kit para análise de estirpes de PVY, fornecido por Agdia (Elkhart, Indiana, Estados Unidos) e utilizado conforme a recomendação do fabricante.

A metodologia de Bagnall \& Tai (1986) foi utilizada para a avaliação da resistência de campo de batata à infecção pelo PVY, com algumas modificações. Os experimentos foram instalados nos períodos de primavera, setembro a dezembro, de 1996 e 1997, em campo da Embrapa Clima Temperado, em áreas isoladas. Cada parcela foi constituída por vinte tubérculos em uma linha de seis metros. O delineamento experimental, com quatro repetições, foi totalmente casualizado. A cada duas linhas de plantio, distanciadas de $80 \mathrm{~cm}$, e nas externas, foram plantados os tubérculos infectados. O plantio e o manejo dos experimentos foram efetuados conforme Bisognin (1996), com exceção do controle de pragas, que não foi efetuado, favorecendo-se a proliferação de insetos.

Tabela 1. Índices de infecção de genótipos de batata pelo vírus Y (Potato virus $Y$ - PVY), após dois plantios consecutivos de primavera, na presença de infectores, em Pelotas, Embrapa Clima Temperado, 1998.

\begin{tabular}{lcccc}
\hline \multicolumn{1}{c}{ Cultivar/Clone } & $\begin{array}{c}\text { Infecção por } \\
\text { PVY }\end{array}$ & Duncan ${ }^{2 /}$ (5\%) & 'SKCA $^{3 /}$ \\
\hline ACHAT & 70 & $\mathrm{a}$ & $\mathrm{MS}$ \\
BINTJE & 51 & $\mathrm{ab}$ & $\mathrm{S}$ \\
CERRITO ALEGRE & 49 & $\mathrm{~b}$ & $\mathrm{~S}$ \\
MONALISA & 45 & $\mathrm{bc}$ & $\mathrm{S}$ \\
SANTO AMOR & 32 & $\mathrm{~cd}$ & $\mathrm{RI}$ \\
ASTRID & 24 & de & $\mathrm{RI}$ \\
MACACA & 24 & de & $\mathrm{RI}$ \\
2 AC 917-7-80 & 24 & de & $\mathrm{RI}$ \\
BARAKA & 22 & de & $\mathrm{RI}$ \\
CATUCHA & 22 & de & $\mathrm{RI}$ \\
TRAPEIRA & 21 & de & $\mathrm{RI}$ \\
BARONESA & 18 & de & $\mathrm{RI}$ \\
MONTE BONITO & 14 & def & $\mathrm{RI}$ \\
CRISTAL & 6 & ef & $\mathrm{R}$ \\
2 CRI 1149-1-79 & 6 & $\mathrm{f}$ & $\mathrm{R}$
\end{tabular}

${ }^{1 /}$ Índice com médias de infecção de quatro parcelas, com dados transformados em arco seno da raiz quadrada de $\mathrm{X} / 100$. Deteç̧ão efetuada por DAS-ELISA, em cinco amostras por parcela, coletadas no final do ciclo de cultivo.

${ }^{2 /}$ Médias seguidas por letras distintas diferem entre si ao nível de $5 \%$ de probabilidade, pelo teste de Duncan.

3/ Análise de agrupamento das cultivares e clones de batata para resistência à infecção pelo PVY, conforme o método de Scott \& Knott (1974). MS = Muito suscetível; S = Suscetível; $\mathrm{RI}=$ Resistente intermediário; $\mathrm{R}=$ Resistente.

No final de cada ciclo de cultivo foi efetuada uma amostragem das parcelas, colhendo-se, aleatoriamente, de cinco plantas por parcela, uma folha central para análise serológica através de DASELISA (Clark \& Adams, 1977), com anti-soro para detecção do PVY disponível na Embrapa Clima Temperado (Daniels et al., 1987). Os tubérculos foram colhidos, classificados e armazenados por cerca de oito meses em câmara fria $\left(4^{\circ} \mathrm{C}, 85 \%\right.$ de umidade relativa), para o plantio seguinte.

A avaliação foi efetuada nos percentuais de infecção acumulados no segundo ano de plantio, após um dos genótipos analisados ter atingido o limite máximo de cem por cento. Usouse a análise da variância dos percentuais de infecção, transformados em arco seno da raiz de $X / 100$, e a análise de agrupamentos, conforme Scott \& Knott (1974). Os genótipos assim agrupados foram denominados de resistente, resistente intermediário, suscetível e muito susce- tível, conforme denominação utilizada por Reifschneider et al. ( 1989).

\section{RESULTADOS E DISCUSSÃO}

Os testes biológicos não foram efetivos para a caracterização das estirpes de PVY presentes nos cinco grupos de infectores, porque em alguns, conforme ficou demonstrado serologicamente, tratava-se de infecção dupla por duas estirpes. Entretanto, o kit serológico foi satisfatório para o fim proposto, revelando a ocorrência de estirpes do grupo $\mathrm{PVY}^{0}$ em três fontes de inóculo e de mistura das estirpes $\mathrm{PVY}^{0}$ e $\mathrm{PVY}^{\mathrm{N}}$ em duas, confirmando a inexistência de proteção cruzada entre estirpes do PVY (Salazar, L. F., Informações Pessoais).

As cultivares e clones testados comportaram-se da seguinte forma: Cristal e 2CRI-1149-1-79, resistentes; Astrid, Baraka, Baronesa, Catucha, Macaca, Monte Bonito, Santo Amor, Trapeira e 2AC-917-7-80, resistentes intermediá- 
rios; Bintje, Cerrito Alegre e Monalisa, suscetíveis; e Achat, muito suscetível (Tabela 1). Os dados obtidos não concordam com as observações realizadas para a cultivar Achat por Reifschneider et al. (1989), que classificaram-na como resistente ao 'Mosaico'. A discrepância poderia ser explicada por uma maior tolerância da cultivar à infecção, o que tornaria os sintomas menos evidentes e passíveis de serem ignorados em observações visuais. Em relação às cultivares holandesas Bintje, Monalisa e Baraka, classificadas no país de origem, para resistência ao $\mathrm{PVY}^{\mathrm{N}}$, com índices de $5 \frac{1}{2}, 8 \frac{1}{2}$ e 8 em uma tabela que varia de 9 (para resistente) a 2 (para muito suscetível) (Catálogo, 1997), as duas primeiras comportaram-se, neste estudo, como resistentes intermediárias e a última como suscetível. O clone 2CRI1149-1-79 revelou-se isento de infecção pelo PVY e foi classificado como resistente, porém pode apresentar imunidade, hipótese que deverá ser testada brevemente.

O objetivo deste trabalho foi determinar a resistência relativa de genótipos de batata ao PVY sob as condições naturais da Região Sul do RS, e não simplesmente selecionar os que apresentassem algum grau de resistência. Embora tenha-se utilizado de um pequeno número de cultivares e clones, a metodologia, embora demorada e trabalhosa, revelou-se eficaz para o objetivo proposto e deverá ser utilizada, também, para acessar a resistência de genótipos de batata ao vírus do enrolamento da folha da batata.

\section{AGRADECIMENTOS}

Agradecemos aos colegas Vera Osório da Fonseca, pela análise estatística dos resultados, Claiton do Amaral Khun e José Idalino do Amaral, pelo apoio técnico na execução dos experimentos a campo e nos testes serológicos, respectivamente.

\section{LITERATURA CITADA}

BAGNALL, R.H.; TAI, G.C.C. Field resistance to potato virus $\mathrm{Y}$ in potato assessed by cluster analysis. Plant Disease, v. 70, n. 4, p. 301-304, 1986.

BISOGNIN, D.A. Recomendações técnicas para o cultivo da batata no Rio Grande do Sul e Santa Catarina. Santa Maria, RS: Universidade Federal de Santa Maria, 1996. 64 p.

CATÁLOGO HOLANDÊS DE VARIEDADES DE BATATA. NIVAA, Den Haag, Holanda. 1997. 270 p.

CLARK, M.F.; ADAMS, A.N. Characteristics of the microplate method of enzyme-linked immunosorbent assay (ELISA) for the detection of plant viruses. Journal of General Virology, v. 34, p. 475-83, 1977.

COSTA, D.M.; CASTRO, L.A.S.; PETERS, J.A. Batata: a busca de maior produtividade. Horti Sul, Pelotas, v. 1, n. 0, p. 40-42, 1989.

DANIELS, J. Produção de batata-semente no Rio Grande do Sul. Horti Sul, Pelotas, v. 3, n. 1, p. 12-15, 1994.

DANIELS, J. Viroses da batata e suas implicações na produção de batata-semente no Rio Grande do Sul. Summa Phytopathologica, Piracicaba, v. 21, n. 3-4, p. 269-270, 1995.

DANIELS, J. Incidência do vírus Y da batata (PVY) em lavouras e em lotes de tubérculos-semente de produtores de São Joaquim, SC e de Bom Jesus, RS, no período 1995/6. In: REUNIÃO TÉCNICA ANUAL DE PESQUISA E EXTENSÃO DA CULTURA DA BATATA NO RIO GRANDE DO SUL E SANTA CATARINA, 3., 1996, Santa Maria, RS. Anais ... Santa Maria, RS, 1996. p. 40 (Resumo).
DANIELS, J.; CASTRO, L.A.S. Incidência de viroses em lavouras de batata do Rio Grande do Sul. Fitopatologia Brasileira, Brasília, v. 9, p. 398, 1984. (Res. 178).

DANIELS, J.; CASTRO, L.A.S.; PAIVA, E.; KULCZYNSKI, S.M. Obtenção e utilização de anti-soro para diagnose do vírus $Y$ da batata. Pelotas, RS: EMBRAPA-CNPFT, 1987. 15 p. (Boletim de Pesquisa, 14).

DELHEY, R. Virus Y and its dynamics in the main potato growing area of Argentina. Fitopatologia, v. 17, n. 1, p. 30-39, 1982.

ELLIS, P.; STACE-SMITH, R.; VILLIERS, G. Identification and geographic distribution of serotypes of potato virus Y. Plant Disease, v. 81, n. 5, p. 481-484, 1997.

FIGUEIRA, A.R. Viroses da batata e suas implicações na produção de batata-semente no estado de Minas Gerais: histórico do problema e soluções. Summa Phytopathologica, Piracicaba, v. 21, n. 3-4, p. 268-269, 1995.

FOXE, M.J. Breeding for viral resistance: conventional methods. Netherland Journal of Plant Pathology, v. 98, p. 13-20, 1992. (Suppl. 2).

McDONALD, J.G.; KRISTJANSSON, G.T. Properties of strains of potato virus $\mathrm{Y}^{\mathrm{N}}$ in North America. Plant Disease, v. 77, n. 1, p. 87-89, 1993.

REIFSCHNEIDER, F.J.B.; LOPES, C.A.; COBBE, R.V. Manejo integrado das doenças de batata. Brasília, DF: CNPHortaliças, 1989. 16 p. (Circular Técnica, 7).

ROSE, D.G.; McCARRA, S.; MITCHELL, D.H. Diagnosis of potato virus $\mathrm{Y}^{\mathrm{N}}$ : a comparison between polyclonal and monoclonal antibodies and a biological assay. Plant Pathology, v.36, n. 1, p. 95-99, 1987.

SCOTT, A.J.; KNOTT, M. A cluster analysis method for grouping means in the analysis of variance. Biometrics, v. 30, p. 507-512, 1974.

SOUZA-DIAS, J.A.C. Viroses da batata e suas implicações na produção de batata-semente no estado de São Paulo. Summa Phytopathologica, Piracicaba, v. 21, n. 3-4, p. 264-266, 1995. 